Article

\title{
Research on Sustainable Development in an Alpine Pastoral Area Based on Equilibrium Analysis Between the Grassland Yield, Livestock Carrying Capacity, and Animal Husbandry Population
}

\author{
Jiping Zhang ${ }^{1}$, Linbo Zhang ${ }^{2}$, Xiaona Liu ${ }^{1}$ and Qing Qiao ${ }^{1, *}$ \\ 1 Beijing Municipal Research Institute of Environmental Protection, Beijing 100037, China \\ 2 Chinese Research Academy of Environmental Sciences, Beijing 100012, China \\ * Correspondence: qiaoqing@cee.cn; Tel.: +86-010-8836-2285
}

Received: 9 July 2019; Accepted: 19 August 2019; Published: 27 August 2019

check for updates

\begin{abstract}
Equilibrium of the grassland yield, livestock carrying capacity, and animal husbandry population is the key factor that influences the ecological environment and sustainable development in pastoral areas. It is of great importance to define the animal husbandry pressure and carrying capacity of an animal husbandry population for grassland management policy-making and the sustainable development of animal husbandry. As one of the areas with the most sensitive and vulnerable ecosystem in China, the Three-River Headwaters Region is an ecological barrier for the environmental security and regional sustainable development of Southeast Asian nations. It is of great significance to define the livestock carrying capacity and population pressure in the area. This research estimates the net primary productivity (NPP) of vegetation in the Three-River Headwaters Region using Carnegie-Ames-Stanford approach (CASA) model, estimates the grass yield on the basis of NPP data, and then estimates the reasonable livestock carrying capacity according to the grass yield. Meanwhile, combined with herdsmen investigation data, it establishes a quantitative relationship between the proper livestock carrying capacity and reasonable animal husbandry population. In addition, the spatial distribution of an overloading animal husbandry population is analyzed through spatial interpolation, which can provide theoretical support for the establishment of scientific ecological immigration policy and the sustainable development of local animal husbandry. The results show that (1) the total grass yield of the grassland in the Three-River Headwaters Region is 13.96 million tons, and the average grass yield is $529.87 \mathrm{~kg} / \mathrm{hm}^{2}$, whilst the spatial distribution presents a decreasing trend from the east and southeast to the west and northwest; (2) the reasonable livestock carrying capacity is 14.03 million sheep units (hereinafter referred as "SU"), and the average livestock carrying capacity is $55.14 \mathrm{SU} / \mathrm{km}^{2}$; and (3) the reasonable animal husbandry population carrying capacity is 512,500 people, while the actual amount is 645,300 , with 132,800 people beyond the carrying capacity, especially in Xinghai, Tongde, Zekog, Yushu, Nangqen, and Chindu County.
\end{abstract}

Keywords: grassland yield; proper livestock carrying capacity; animal husbandry population; herdsmen investigation; Three-River Headwaters Region

\section{Introduction}

As an important part of the Tibetan Plateau, the source area of the Yangtze River, Yellow River, and Lancang River, known as Three-River Headwaters in China, is the ecological security barrier for the middle and lower reaches of rivers in China and Southeast Asian Nations. The geographic environment and climatic conditions in the area are extremely unique and it has the most sensitive and fragile ecosystem in China [1-3]. The ecosystem protection and ecosystem changes under global 
change in this region have attracted increasing research concern [4-6]. In recent decades, because of the composite effects of climate change and unreasonable human disturbance, such as overgrazing and disorder excavation, grassland has been seriously degraded in the area $[7,8]$. The degraded grassland area accounts for $26-46 \%$ of the usable grassland area in the Headwaters Region [9,10]. Grassland degradation seriously impacts the sustainable development of the regional ecological environment and grassland husbandry, and severely threatens the ecological security of other related areas.

The grassland ecosystem is the dominant ecosystem in the Three-River Headwaters Region, occupying about $70 \%$ of the total area [4]. Animal husbandry is the leading industry in this region, and the animal husbandry population occupies more than $90 \%$ of the total population [11-13]. Although the total animal husbandry population of the Tibetan Plateau is relatively lower, due to very easy policy on population birth which has been implemented since 1949, the animal husbandry population has maintained a high natural growth rate in the long term. Therefore, the population pressure impacts productivity more prominently. The overloading phenomenon is severe, with an average overloading rate of $250 \%$, almost covering over $80 \%$ of the counties in the study area $[14,15]$. Meanwhile, to promote restoration of the grassland ecosystem, the Chinese government has successively carried out some ecological protection and construction projects, such as the "Grain for Green" project, the integrated management of degraded grass land, and ecological migration [16,17]. The ecological migration project has received widespread concerns. Ecological migration in the Three-River Headwaters Region has mainly focused on herdsmen immigration according to actual regional situations, emigration and immigration conditions, and the intentions of herdsmen. By the end of 2015, the total scale of ecological migration reached about 20,000 households, including 100,000 persons. The ecological migration project has played an important role in ecological environment improvement in this area. However, since the ecological migrants in villages and towns have been relocated as a whole, and the consideration of animal husbandry pressure and the spatial distribution of the carrying capacity of the animal husbandry population is poor, it is difficult to develop the follow-up industry, and the eco-compensation is inadequate. Therefore, some ecological immigrants still have difficulties in their production and life, and they finally return to grazing. The ecological migration project has not fully played out the proper effects of reducing grazing and livestock. Therefore, it is necessary to further research the carrying capacity of the animal husbandry population on the basis of the grassland-livestock balance, define its spatial distribution, and realize the people-grassland-livestock coordination on both a quantity and space scale, so as to ensure the scientific grassland policy and promote the harmonious development between humans and grassland.

Equilibrium of the grassland yield, livestock carrying capacity, and animal husbandry population is the key factor that influences the ecological environment and sustainable development of pastoral areas, so it is of great significance to study the regional population-grassland-livestock balance for making regional policies. At present, some scholars have carried out related research on the population carrying capacity of pastoral areas [18-21]. These studies mainly calculated the population carrying capacity using the statistical data to divide physical indicators (e.g., grain yield and meat production) by per capita possession, or divide value indicators (e.g., regional gross domestic product (GDP)) by per capita standard. Meanwhile, due to the limited research techniques and lack of application of technical means, such as remote sensing, the estimated results of the population carrying capacity are only expressed in numerical form, which cannot reflect the spatial distribution characteristics of the population carrying capacity. The existing research on the population carrying capacity in pastoral areas has failed to analyze the population, grassland, and livestock as a whole. These studies have mostly focused on the available total material and per capita consumption, while ignoring whether the available total material is "reasonable" or not. Additionally, they have ignored whether the livestock product was offered at the cost of ecological environment destruction. To make the estimated results of population carrying capacity more scientific and specific, it is necessary to take population, grassland, and livestock as a whole, and realize the "population determined according to livestock" on the basis of the "livestock determined according to grassland". On one hand, it can reflect the spatial distribution 
characteristics of the carrying capacity of the animal husbandry population; on the other hand, it can closely combine the carrying capacity of the animal husbandry population with the grassland grazing capacity, so that the estimated grazing capacity of the animal husbandry population can satisfy the bottom line that the grassland does not deteriorate due to overgrazing, so the estimated result has better practical significance. However, the related research is insufficient in this field. At the same time, due to the lack of research on the accurate interpolation of statistical data about the population and livestock etc., the related research has mainly emphasized changes against a time scale, and hardly the spatial distribution of the population [22-24].

Although research on the population carrying capacity has made significant progress, research on the pastoral population carrying capacity still has a weak theoretical basis and uses, as well as imperfect regulation mechanisms and estimation methods. There are studies on the grassland-livestock balance [25,26], and some studies have focused on the wellbeing and livelihood of herdsmen [27,28]. How to combine the two aspects of research to better reveal the internal coupling relationship needs to be studied in depth. This research employs an element of "population" to combine research on the regional ecological environment with regional social and economic factors. This study establishes a quantitative relationship between the proper livestock carrying capacity and suitable animal husbandry population, and then defines the reasonable scale and spatial distribution characteristics of the animal husbandry population in this area with high-precision spatial interpolation for statistical data by means of a geographic information system (GIS). Such results can provide a basis for governments at all levels to understand the equilibrium of grassland-livestock-population in the study area, so as to issue policies on grassland and offer relevant ecological protection construction. Therefore, it is of great importance to realize the sustainable management of a grassland ecosystem, reasonable grazing, optimized population arrangement, and the sustainable development of animal husbandry in the Three-River Headwaters Region.

\section{Data and Methods}

\subsection{Study Area}

The Three-River Headwaters Region is located between $89^{\circ} 45^{\prime} \mathrm{E} \sim 102^{\circ} 23^{\prime} \mathrm{E}$ and $31^{\circ} 39^{\prime} \mathrm{N} \sim 36^{\circ} 12^{\prime} \mathrm{N}$, with a total area of $363,000 \mathrm{~km}^{2}$ (Figure 1). The Three-River Headwaters Region is the central region and main body of the Tibetan Plateau, with an elevation of 3335-6564 m. This area belongs to the Tibetan Plateau Climate System, which is a typical plateau continental climate. The average temperature is $-5.6-3.8^{\circ} \mathrm{C}$. The average annual precipitation is $262.2-772.8 \mathrm{~mm}$, and the annual evaporation is $730-1700 \mathrm{~mm}$. Due to the high altitude, most of the regions are featured as the rarefied air and short plant growth period. Alpine meadow and alpine grassland are the main vegetation types in this area. The regional soil distribution presents obvious vertical zonal rules, with mainly alpine meadow soil, secondly swamping meadow soil, and extremely developed permafrost [15,29].

\subsection{Estimation of Grassland Yield}

The Carnegie-Ames-Stanford Approach (CASA) [30,31] was used to estimate the net primary productivity (NPP) of grassland from 2000 to 2015. The grassland yield was estimated on the basis of the annual mean NPP. The CASA model, a process-based model based on the concept of light-use efficiency, is suitable for estimating vegetation NPP at both regional and global scales [32-35]. The input data of the model included MODIS NDVI data (with the resolution of $1 \mathrm{~km}$ ) of growing season (April to August) from 2000 to 2015, and meteorological data were downloaded from China Meteorological Data Network (http://data.cma.cn/). The land cover data was obtained from the 1:100,000 land use data set shared by the Institute of Geographical Sciences and Natural Resources Research, Chinese Academy of Sciences. The grassland yield was estimated through the ratio between the underground and aboveground productivity of all kinds of grassland vegetation $[15,36,37]$. 


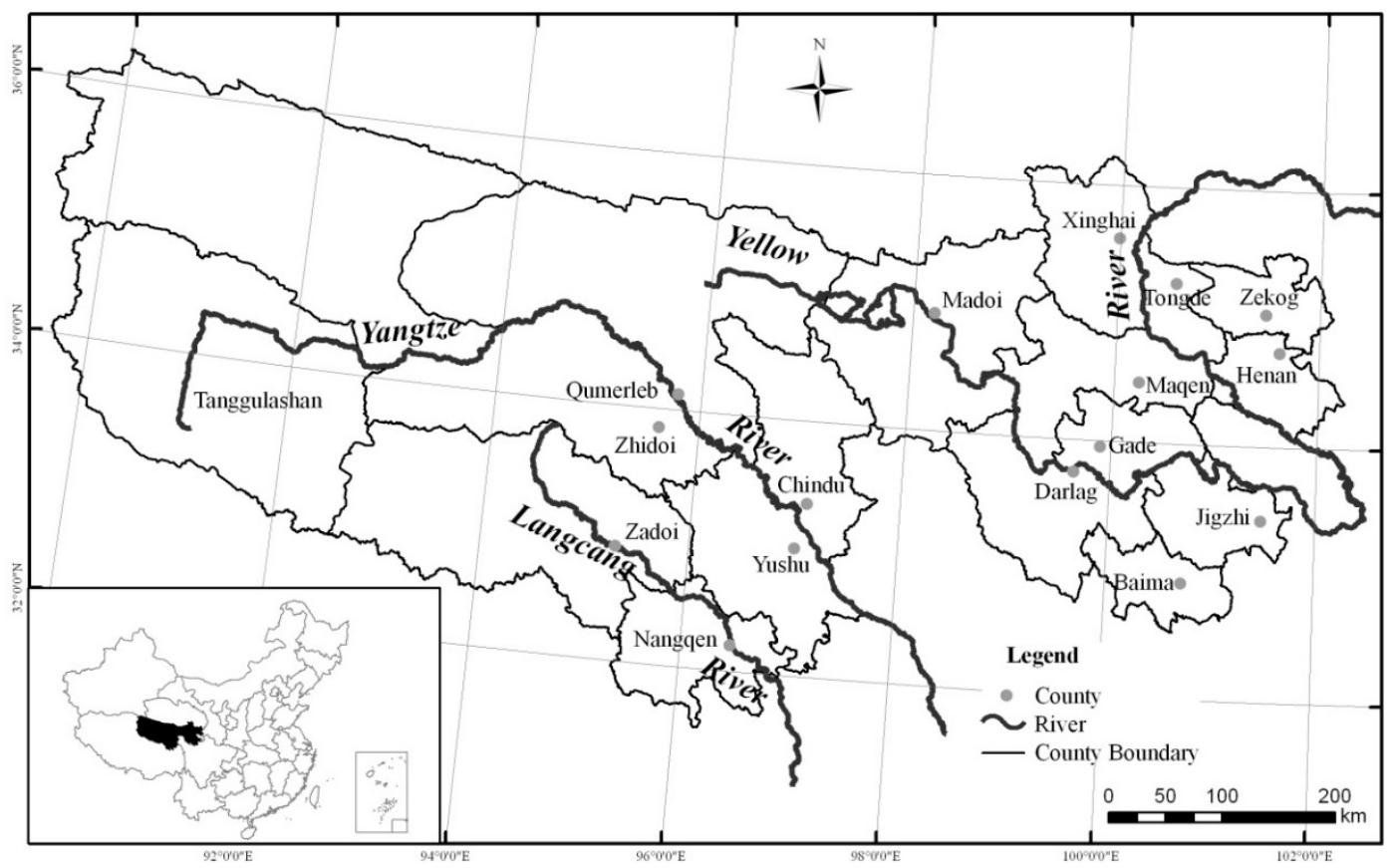

Figure 1. Location of the Three-River Headwaters Region.

\subsection{Estimation of Proper Livestock Carrying Capacity}

The proper carrying capacity was calculated by the following formula [38]:

$$
C l=\frac{Y_{m} \times C_{o}}{S_{f} \times G_{t}}
$$

where $\mathrm{Cl}$ is the proper livestock carrying capacity (standard SU/hm ${ }^{2}, \mathrm{SU}$ is short for sheep unit; $\mathrm{hm}^{2}$ is short for square hectometer); $Y_{m}$ is the grassland yield $(\mathrm{kg}) ; C_{o}$ is the grassland utilization ratio and $S_{f}$ is the daily food intake per SU livestock, both of which are determined according to the relevant standard [39]; and $G_{t}$ is the grassland grazing time. The pasture in the study area can be divided into two categories: (1) cold season pasture and (2) warm season pasture. The spatial distributions of the two pastures were obtained through digitization of the Atlas of Rangeland Resources of China. The grazing time of the cold season pasture and the warm season pasture is 210 days and 155 days, respectively.

\subsection{Herdsmen Investigation and Estimation of the Reasonable Animal Husbandry Population Carrying Capacity}

From the perspective of grazing pressure on the pasture resources, this study takes the proper carrying capacity of grassland resources in the study area as the total amount of primary goods to guarantee human survival and development, with the precondition of no grassland degradation due to overgrazing, and calculates the total amount of livestock required to maintain a normal life of a herdsman in the current living standard in one year (in sheep unit) on the basis of survey data on herdsmen. It is regarded as the per capita consumption. The reasonable animal husbandry population carrying capacity of grassland resources can then be estimated according to the total amount of primary goods and per capita consumption.

The international stratified random sampling method [40,41] is adopted in this study for the herdsmen investigation process. We chose six typical counties according to the representation, transportation condition, and field work convenience. We selected three typical villages from each typical county, and 30 herder households from each typical village, for investigation. In April to July 2015, our research group interviewed the relevant departments (Qinghai Provincial Department of Agriculture and Animal Husbandry, Provincial Department of Statistics, Provincial Forestry Department, Provincial 
Department of Science \& Technology, Animal Husbandry Bureau, Statistics Bureau, and Forestry Bureau of each county, etc.) of the study area, and conducted a herdsmen investigation of six counties in the Three-River Headwaters Region, including Zekog, Maqen, Madoi, Chindu, Zadoi, and Yushu County. We collected 504 effective questionnaires in sum.

The investigation contents mainly included the following:

1. Basic background information of herdsmen, including family population, gender, age, education level, etc.;

2. Living consumption of herdsmen, including food, clothing and housing, household equipment and supplies, transportation and communication, culture, education and entertainment, health care, other goods and services, etc.;

3. Livestock breeding, including livestock quantity and species, population structure, slaughtering rate, mortality rate, sell and self-consumption, and so on;

4. Grassland utilization conditions, including grassland area and distribution (GPS survey), grassland quality, use mode, and use intensity;

5. Livestock product price, including the sale price of all kinds of livestock and livestock products.

Based on survey data of herdsmen and statistical analysis, the relevant information can be determined, including the grazing capacity per capita (sheep unit), self-consumption of livestock (sheep unit), and slaughtering rate, and the conversion relationship can be established between the herdsmen's expenditures and sheep unit according to the sale price of an adult sheep (i.e., one sheep unit). Based on the basic living cost per herdsman and livestock slaughtering rate, the total livestock breeding amount (in sheep unit) require to maintain the normal life of a herdsman for one year can be calculated. Combined with the proper livestock carrying capacity of grassland resources computed above, the animal husbandry population that can be carried by grassland resources in the study area under current living standards can be calculated. The formula below can be followed:

$$
P=S / C
$$

where, $P$ is the animal husbandry population which can be carried by grassland resources; $S$ is the proper carrying capacity (sheep unit); and $C$ is the basic living cost per herdsman (sheep units/year/person), which refers to the total amount of livestock breeding (in sheep unit) required to maintain the normal life need of a herdsman for one year:

$$
C=(E+D / U) / R
$$

where, $E$ is the self-consumption of livestock per herdsman per year (in sheep unit); $D$ is the sum of expenditures per herdsmen per year (RMB/year/person); $U$ is the sale price of an adult sheep (i.e., one sheep unit); and $R$ is the livestock slaughtering rate.

\subsection{Spatialization of Statistics Data on Animal Husbandry Population}

The spatial distribution data of the animal husbandry population in the Three-River Headwaters Region can be obtained by spatial interpolation of statistics data of the animal husbandry population in 2015. The basic data includes digital elevation model (DEM) data with the resolution of $90 \mathrm{~m} \times 90 \mathrm{~m}$, county-level administrative division maps, residential and grazing spot distribution data (from 1:250,000 topographic map data), and county-level animal husbandry population statistics. The densities of the animal husbandry population in towns and villages and grazing points of each county can be determined through residential distribution data and statistics of the animal husbandry population, together with relevant literature and material. Based on such density data, the densities of the animal husbandry population can be interpolated (with a resolution of $1000 \mathrm{~m}$ ) under the platform of ArcGIS(Environmental Systems Research Institute, Redlands, CA, USA) v10.1 by means of the inverse-distance weighted method combinined with DEM data (to control the upper limit of the 
population distribution). Meanwhile, we can consider the waters and deserts as uninhabited area, and take the vegetation distribution area as the interpolation mask.

\section{Results}

\subsection{Spatial Distribution of Grassland Yield}

The total grassland yield (hay) of the study area is 13.96 million tons; the average grassland yield (hay) is $529.87 \mathrm{~kg} / \mathrm{hm}^{2}$. The spatial distribution presents a decreasing trend from the east and southeast to the west and northwest in turn (Figure 2). In this region, the spatial distribution of grassland yield is consistent with distribution rules of temperature and precipitation. A high grassland yield appears in the area with a high air temperature and precipitation.

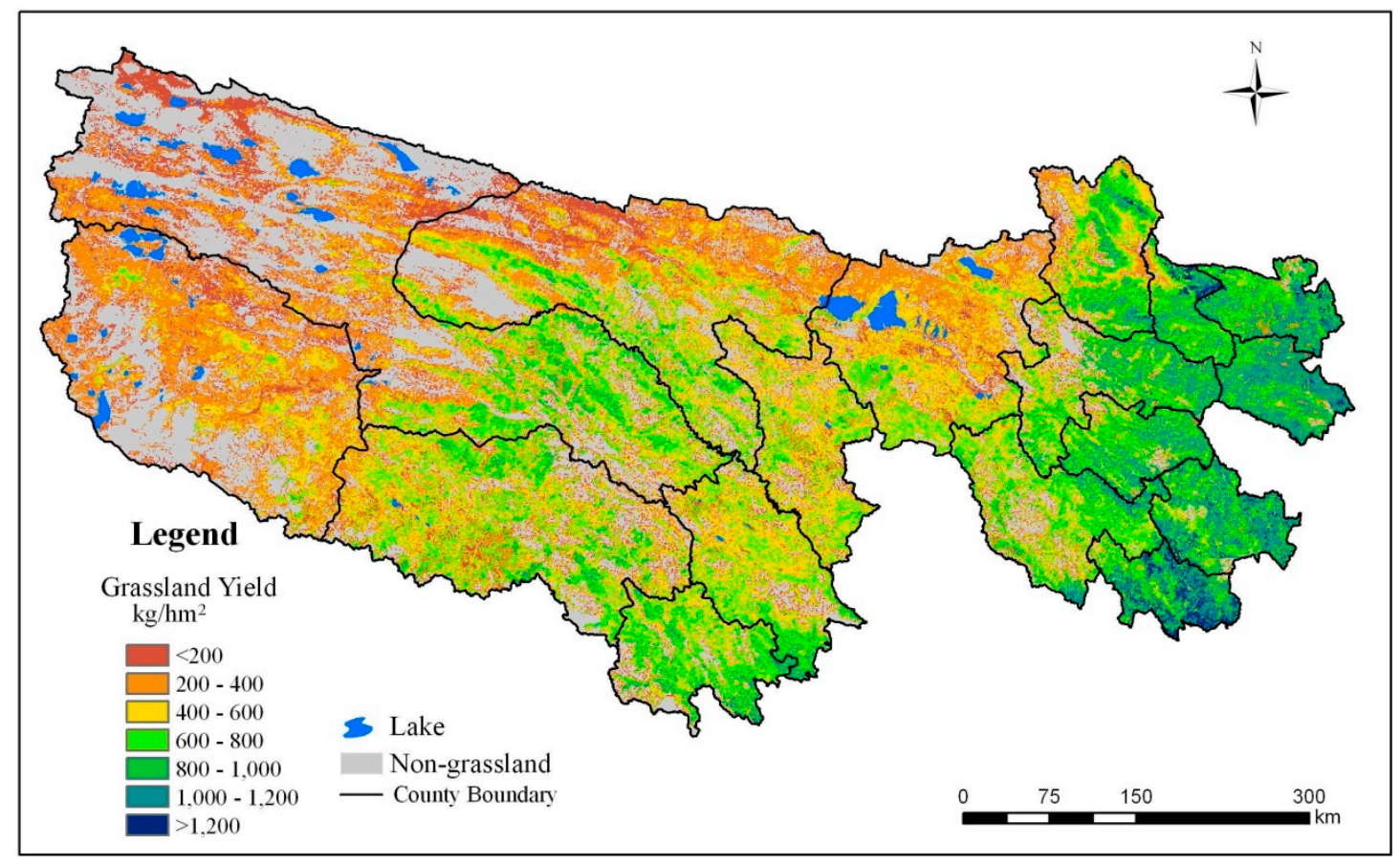

Figure 2. Distribution of the grassland yield of the Three-River Headwaters Region.

\subsection{Spatial Distribution of Proper Livestock Carrying Capacity}

The proper carrying capacity of the study area is 14.52 million SUs, which is in accordance with the data (14.03 million SUs) provided by the Agriculture and Animal Husbandry Department of Qinghai Province. The average livestock carrying capacity reaches $55.14 \mathrm{SU} / \mathrm{km}^{2}$. There is a good consistency between the distribution of the livestock carrying capacity and the grass yield (Figure 3).

\subsection{Reasonable Animal Husbandry Population Carrying Capacity}

It is shown from herdsmen investigation data that the average price of an adult sheep (that is, a sheep unit) is RMB 1000; meat consumption per person per year of the local herdsmen is about $80 \mathrm{~kg}$, equal to $5.5 \mathrm{SUs}$; and per capita consumption of other daily necessities is approximately RMB 3100, which is about 3 SUs. Therefore, based on the current local living conditions, the basic living cost per herdsman of each year is $8.5 \mathrm{SUs}$. It is indicated from the investigation data that the average slaughtering rate of local livestock is $30 \%$. According to the calculation results, total 28.33 SUs of livestock must be bred to maintain the normal life of a herdsman. In combination with the total proper livestock carrying capacity of the study area obtained above, the reasonable animal husbandry population carried by the natural grassland in the Three-River Headwaters Region is 512,500 under the current living conditions. 


\subsection{Spatial Distribution of Animal Husbandry Population Beyond Carrying Capacity}

According to the Qinghai Province Statistical Yearbook, the total animal husbandry population in the Three-River Headwaters Region amounts to 645,300 by the end of 2015, while our research found that the reasonable animal husbandry population carrying capacity is just 512,500 , so 132,800 people are beyond the carrying capacity. Through the spatial interpolation of statistics of the animal husbandry population, the spatial distribution of the actual animal husbandry population can be obtained. The spatial distribution of the reasonable animal husbandry population can be derived through the spatial distribution data of the proper livestock carrying capacity. The spatial distribution of the overloading animal husbandry population can be calculated through spatial subtraction of the two (Figure 4). It is shown from Figure 4 that there is a significant spatial difference of the overloading animal husbandry population. The overloading amount is relatively larger in six counties, including Xinghai, Tongde, Zekog, Nangqen, Yushu, and Chindu, and is less in other areas. For broad central and western regions, the actual animal husbandry population has not yet reached the reasonable animal husbandry population and has a certain carrying capacity of the animal husbandry population.

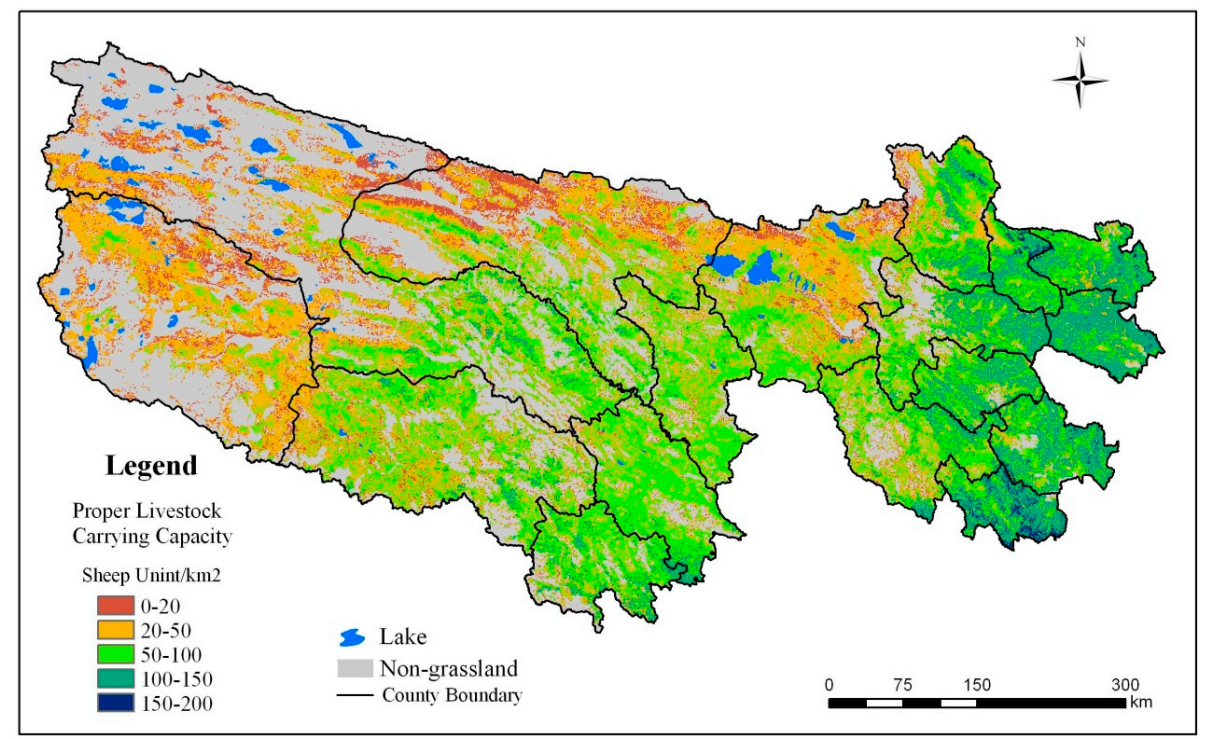

Figure 3. Distribution of the proper carrying capacity of grassland of the Three-River Headwaters Region.

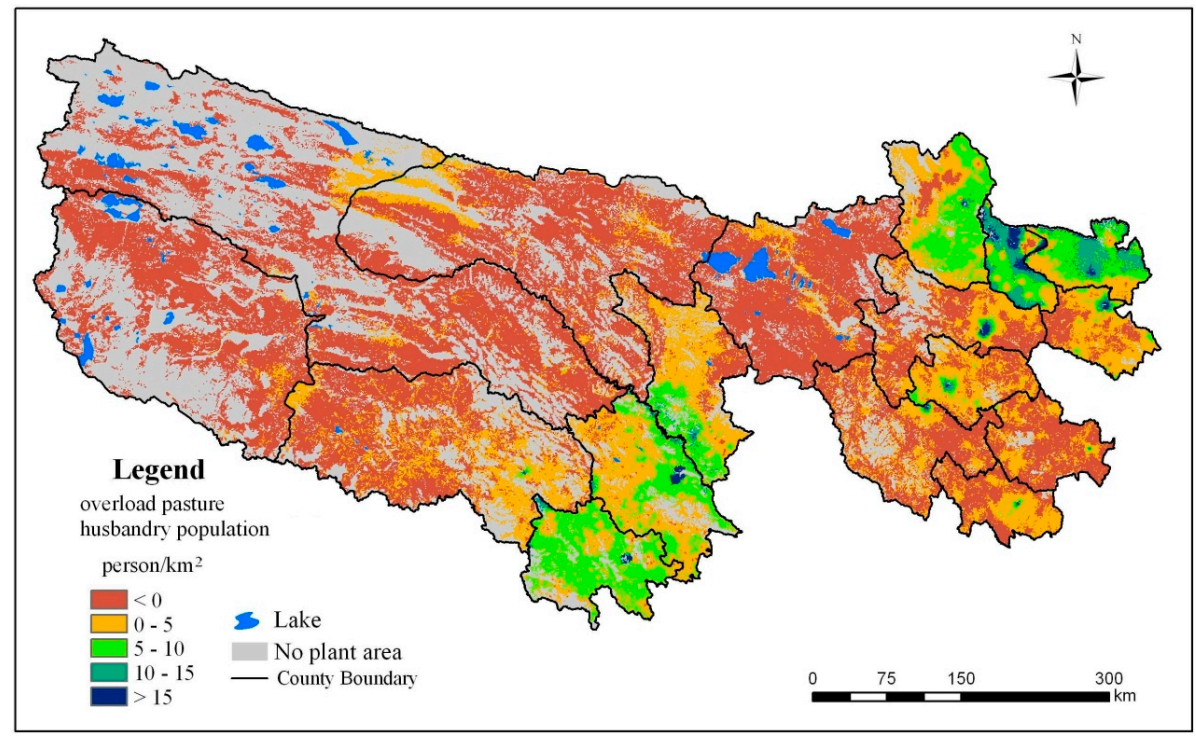

Figure 4. Distribution of the overloading animal husbandry population of the study area. 


\section{Discussion and Conclusions}

Our result of the average grassland yield in the Three-River Headwaters Region is slightly higher than Fan (442.5 kg/hm²) [36], mainly due to the different research periods (Fan: 1988-2005), data sources (Fan: NOAA/AVHRR data), and models (Fan: GLO-PEM model). It is reported by many studies that both the average temperature and precipitation in the Three-River Headwaters Region have somewhat increased under the impact of global climate change, which is helpful for grass growth and leads to an increase of grassland productivity [42-44]. Therefore, the grassland yield in 2000-2015 shall be higher than that in 1988-2005. The calculation results of the grassland yield in this paper are consistent with such law with certain credibility.

Our result of the average proper carrying capacity of the study area is also slightly higher than that of $\operatorname{Fan}\left(44 \pm 5 \mathrm{SU} / \mathrm{km}^{2}\right)$ [36]. This is mainly due to the differences in the overgrazing number results and the calculation process of the average proper carrying capacity. In our research, the grassland utilization ratio is determined according to the specified value for each grassland category under the national standard [39], while Fan [36] did not consider the difference between grasslands.

This study uses the DEM, distribution data of residential areas and grazing spots, statistics data of the animal husbandry population at a county level, and land use data to interpolate the statistics of the animal husbandry population by the GIS spatial interpolation tool. The interpolated result can objectively reflect the spatial distribution of the animal husbandry population to a certain degree. However, the distributions of roads and rivers are also important factors influencing the spatial distribution of the animal husbandry population. All factors shall be comprehensively taken into account and more rigorous mathematical methods shall be used to realize accurate interpolation in future research.

During herdsmen investigation, it is hard for the sampling study to fully reflect the actual situations due to the great difference of herdsmen households. In addition, the data acquisition or completeness is limited by time and region; the household investigation is influenced by the scattered villages or settlements, inconvenient traffic, free time, attitude, or initiative of herdsmen household. In addition, a language barrier still exists, so local interpretation assistance is required to understand Tibetan, which inevitably leads to deviations and misunderstanding that affect the accurate acquisition of information and data.

In this study, the reasonable animal husbandry population carrying capacity was determined under the assumption that almost all the living consumption of herdsman was obtained from the husbandry income. In order to improve the estimation accuracy, the diversity of herdsman incomes should be considered in future study. The ratio of the husbandry income for the total income could be adopted as a coefficient to revise the estimation of the reasonable animal husbandry population carrying capacity. Follow up research should place a more variable focus on the life and business opportunities of the local herdsmen.

The animal husbandry in the study area remains in an original or semi-original state. The animal husbandry totally relies on grassland and pasture. Traditional animal husbandry production methods are too rough and lack scientific management. On one hand, it is extremely unfavorable to increase the quantity of animal products; on the other hand, the unreasonable utilization intensifies grassland degradation, which causes regional ecological deterioration. Growth of the population exerts great pressure on local productivity, together with lagging ideological concepts and a lack of modern commodity economy awareness (many people do not sell age-appropriate livestock in time, resulting in too much livestock on hand), which also intensify the overgrazing, and accordingly, the ecological environment tends to deteriorate. To solve this problem, the animal husbandry population should be well arranged, the livestock must be reduced, and the scientific management method and modern consciousness of the commodity economy should be popularized.

This study has estimated the grass yield on the basis of NPP data and calculated the proper livestock carrying capacity in the Three-River Headwaters Region. Meanwhile, it has established a quantitative relationship between the proper livestock carrying capacity and reasonable animal 
husbandry population based on herdsmen investigation data. In addition, the spatial distribution of the overloading animal husbandry population in the study area has been analyzed through spatial interpolation. The reasonable animal husbandry population carrying capacity in the study area is 512,500 , with 132,800 people beyond the carrying capacity. In view of the serious overloading animal husbandry population in the Three-River Headwaters Region, it is suggested that the management of animal husbandry in the region should focus on equilibrium of the grassland yield, livestock carrying capacity, and animal husbandry population, and adhere to the principle of "determining livestock according to grassland and determining population according to livestock". On one hand, the policy of livestock reduction and livestock slaughtering rate improvement shall be continuously implemented to control the livestock amount, so as to alleviate grazing pressures, promote the scientific method for raising livestock, and ensure the healthy development of the grassland ecosystem. On the other hand, in order to realize the equilibrium of "population-grassland-livestock" and promote regional sustainable development of animal husbandry in this region, macro-regulation of the animal husbandry population shall be carried out to promote herdsmen in the areas with severe grassland degradation to tertiary industry through ecological migration or production transformation in situ, so that they are no longer engaged in traditional animal husbandry.

Author Contributions: Conceptualization, J.Z. and L.Z.; Methodology, J.Z. and Q.Q.; Software, J.Z. and X.L.; Validation: J.Z., L.Z., Q.Q. and X.L.; Formal analysis, J.Z. and Q.Q.; Investigation, J.Z. and L.Z.; Resources, J.Z. and L.Z.; Data curation, J.Z. and X.L.; Writing-original draft preparation, J.Z; Writing—review and editing, Q.Q.; Visualization, J.Z. and X.L.; Supervision, Q.Q.; Project administration, J.Z.; Funding acquisition, J.Z.

Funding: The work was supported by the National Natural Science Foundation of China (41701209, 41501095).

Conflicts of Interest: The authors declare no conflicts of interest.

\section{References}

1. Zhao, X.; Zhou, H. Eco-Environmental degradation, vegetation regeneration and sustainable develo-pment in the Headwaters of Three Rivers on Tibetan Plateau. Bull. Chin. Acad. Sci. 2005, 20, 471-476.

2. Zhang, Y.; Liu, L.; Bai, W.; Shen, Z.; Yan, J.; Ding, M. Grassland degradation in the source region of the yellow river. Acta Geogr. Sin. 2006, 61, 3-14.

3. Li, H.; Liu, G.; Fu, B. Response of vegetation to climate change and human activity based on ndvi in the three-river headwaters region. Acta Ecol. Sin. 2011, 31, 5495-5504.

4. Xu, X.; Liu, J.; Shao, Q.; Fan, J. The dynamic changes of ecosystem spatial pattern and structure in the Three-River Headwaters region in Qinghai Province during recent 30 years. Geogr. Res. 2008, 27, 829-838.

5. Yi, X.; Li, G.; Yin, Y. Temperature variation and abrupt change analysis in the Three-River Headwaters Region during 1961-2010. J. Geogr. Sci. 2012, 22, 451-469. [CrossRef]

6. Wang, X.; Zhagn, Y. Emergy-Based Evaluation of Changes in Agrochemical Residues on the Qinghai-Tibet Plateau, China. Sustainability 2019, 11, 3652. [CrossRef]

7. Wang, G.; Chegn, G. Eco-environmental changes and causative analysis in the source regions of the Yangtze and Yellow Rivers, China. Environmentalist 2000, 20, 221-232.

8. Feng, J.; Wang, T.; Xie, C. Eco-environmental degradation in the source region of the yellow river, northeast Qinghai Xizang plateau. Environ. Monit. Assess. 2006, 122, 125-143. [CrossRef]

9. Yang, J.; Ding, Y.; Chen, R. Spatial and temporal of variations of alpine vegetation cover in the source regions of the Yangtze and Yellow Rivers of the Tibetan Plateau from 1982 to 2001. Environ. Geol. 2006, 50, 313-322. [CrossRef]

10. Liu, J.; Xu, X.; Shao, Q. Grassland degradation in the "Three-River Headwaters" region, Qinghai Province. J. Geogr. Sci 2008, 18, 259-273. [CrossRef]

11. Zhou, Y. Evaluation model of Qinghai grassland resources. Chin. Agric. Meteorol. 1997, 18, 38-40.

12. Liu, J.; $\mathrm{Xu}, \mathrm{X}$.; Shao, Q. The spatial and temporal characteristics of grassland degradation in the Three-River Headwaters Region in Qinghai Province. J. Geogr. Sci 2004, 63, 364-376.

13. Zhou, H.; Zhao, X.; Zhou, L.; Tang, Y.; Liu, W.; Shi, Y. Application of analytic hierarch y process on the alpine grassland degradation in the source region of the Yangtze and Yellow Rivers. Resour. Sci. 2005, 27, 63-70. 
14. Wu, H.; An, R.; Li, X.; Qu, C.; Lu, L.; Yang, R.; Gong, T. Remote sensing monitoring of grassland degradation based on NPP change in the Maduo County of the sources region of Yellow River. Pratac. Sci. 2011, 28, 536-542.

15. Zhang, J.; Zhang, L.; Liu, W.; Qi, Y.; Wo, X. Livestock Carrying Capacity and Overgrazing Status of Alpine Grassland in Three-River Headwaters Region. J. Geogr. Sci 2014, 24, 303-312. [CrossRef]

16. Qian, S.; Mao, L.; Hou, Y.; Fu, Y.; Zhagn, H.; Du, J. Livestock Carrying Capacity and Balance between Carrying Capacity of Grassland with Added For age and Actual Livestock in the Qinghai-Tibet Plateau. J. Nat. Resour. 2007, 22, 389-397.

17. Fan, J.; Shao, Q.; Wang, J.; Chen, Z.; Zhong, H. An Analysis of Temporal spatial Dynamics of Grazing Pressure on Grassland in Three Rivers Headwater Region. Chin. J. Grassl. 2011, 33, 64-72.

18. Robert, C. Economic growth, carrying capacity, and the environment. Ecol. Econ. 1995, 15, 89-90.

19. Komatsu, Y.; Tsunekawa, A.; Ju, H. Evaluation of agricultural sustainability based on human carrying capacity in dry land-acase study in rural villages in Inner Mongolia, China. Agric. Ecosyst. Environ. 2005, 108, $29-43$. [CrossRef]

20. Yu, W.; Qu, F.; Qi, Y.; Liu, P.; Shi, J. Population Carrying Capacity of Land Resources in Qinghai Lake Area. Bull. Soil Water Conserv. 2009, 29, 74-78.

21. Xiang, H.; Yang, J.; Liu, X.; Lee, J. Balancing Population Distribution and Sustainable Economic Development in Yangtze River Economic Belt of China. Sustainability 2019, 11, 3320. [CrossRef]

22. Liao, S.; Sun, J. GIS based spatialization of population census data in Qinghai-Tibet Plateau. J. Geogr. Sci. 2003, 58, 25-33.

23. Zhou, X.; Wang, Z.; Zhang, X.; Li, C.; Jiu, C.; Chen, Q. Spatial distribution of population based on interpolation and its application in the farming-pastoral transition regions. Pratac. Sci. 2010, 27, 143-152.

24. Ma, L.; Chen, M.; Che, X.; Fang, F. Research on Population-Land-Industry Relationship Pattern in Underdeveloped Regions: Gansu Province of Western China as an Example. Sustainability 2019, 11, 2434. [CrossRef]

25. Thapa, G.B.; Paudel, G.S. Evaluation of the livestock carrying capacity of land resources in the Hills of Nepal based on total digestive nutrient analysis. Agric. Ecosyst. Environ. 2000, 78, 223-235. [CrossRef]

26. Mckeon, G.M.; Stone, G.S.; Syktus, J.I. Climate change impacts on northern Australian rangeland livestock carrying capacity: a review of issues. Rangel. J. 2009, 31, 1-29. [CrossRef]

27. Ding, W.; Saheed, O.J.; Hou, Y.; Hou, X.; Zhang, W. Influence of Livelihood Capitals on Livelihood Strategies of Herdsmen in Inner Mongolia, China. Sustainability 2018, 10, 3325. [CrossRef]

28. Dong, X.; Dai, G.; Sergio, U.; Risu, N.; Zhang, X.; Kang, M.; Wang, X. On the Relationship between Economic Development, Environmental Integrity and Well-Being: The Point of View of Herdsmen in Northern China Grassland. PLOS ONE 2015, 10, 1-23. [CrossRef]

29. Li, H.; Liu, G.; Fu, B. Estimation of Regional Evapotranspiration in Alpine Area and Its Response to Land Use Change: A Case Study in Three-River Headwaters Region of Qinghai-Tibet Plateau, China. Chin. Geogr. Sci. 2012, 22, 437-449. [CrossRef]

30. Potter, C.; Randerson, J.T.; Field, C.B.; Matson, P.A.; Vitousek, P.M.; Mooney, H.A.; Klooster, S. Terrestrial ecosystem production: A process model based on global satellite and surface data. Glob. Biogeochem. Cycles 1993, 7, 811-841. [CrossRef]

31. Field, C.B.; Randerson, J.T.; Malmstrom, C.M. Global net primary production: Combining ecology and remote sensing. Remote Sens. Environ. 1995, 51, 74-88. [CrossRef]

32. Liu, J.; Chen, J.; Cihlar, J.; Chen, W. Net primary productivity distribution in the BOREAS region from a process model using satellite and surface data. J. Geophys. Res. 1999, 104, 735-754. [CrossRef]

33. Fang, J.; Piao, S.; Field, C.B.; Pan, Y.; Guo, Q.; Zhou, L.; Peng, C.; Tao, S. Increasing net primary production in China from 1982 to 1999. Front. Ecol. Environ. 2003, 1, 293-297. [CrossRef]

34. Zhu, W.; Pan, Y.; Liu, X.; Wang, A. Spatio-temporal distribution of net primary productivity along the northeast China transect and its response to climatic change. J. For. Res. 2006, 17, 93-98. [CrossRef]

35. Yu, D.; Shi, P.; Shao, H.; Zhu, W.; Pan, Y. Modelling net primary productivity of terrestrial ecosystems in East Asia based on an improved CASA ecosystem model. Int. J. Remote Sens. 2009, 30, 4851-4866. [CrossRef]

36. Fan, J.; Shao, Q.; Liu, J.; Wang, J.; Chen, Z.; Zhong, H.; Xu, X.; Liu, R. Dynamic Changes of Grassland Yield in Three River Headwater Region from 1988 to 2005. Acta Agrestia Sin. 2010, 18, 5-10. 
37. Gill, R.A.; Kelly, R.H.; Parton, W.J.; Day, K.A.; Jackson, R.B.; Morgan, J.A.; Scurlock, J.M.O.; Tieszen, L.L.; Castle, J.V.; Ojima, D.S.; et al. Using simple environmental variables to estimate below -ground productivity in grass -lands. Glob. Ecol. Biogeogr. 2002, 11, 79-86. [CrossRef]

38. Lin, B.; Sha, Z.; Tan, S.; Sun, Z.; Wang, M. Research progress in methodologies for carrying capacity and proper stocking rate in grassland ecological system. Pratac. Sci. 2008, 25, 91-99.

39. NY/T 635-2002. Agriculture Industry Standard of the People' s Republic of China-Calculation of Proper Carrying of Range Land. Available online: https://www.docin.com/p-1755634759.html (accessed on 12 August 2012).

40. Cramb, R.A.; Purcell, T.; Ho, T.C.S. Participatory assessment of rural livelihoods in the Central Highlands of Vietanam. Agric. Syst. 2004, 81, 255-272. [CrossRef]

41. Kangalawe, R.; Liwenga, E. Livelihoods in the wetlands of Kilombero Valley in Tanzania: Opportunities and challenges to integrated water resource management. Phys. Chem. Earth 2005, 30, 968-975. [CrossRef]

42. Li, L.; Li, F.; Guo, A.; Zhu, X. Study on the climate change trend and its catastrophe over "Sanjiangyuan" Region in recent 43 years. J. Nat. Resour. 2006, 21, 79-85.

43. Qian, S.; Fu, Y.; Pan, F. Climate change tendency and grassland vegetation response during the growth season in Three-River Source Region. Sci China Earth Sci. 2010, 53, 1506-1512. [CrossRef]

44. Zhang, J. Changes of Wetland and NPP of Wetland Vegetation in Damqu River Basin in Source Region of the Yangtze River and the Influencing Factors. Ph.D. Thesis, Institute of Geographic Sciences and Natural Resources Research, Chinese Academy of Sciences, Beijing, China, June 2011.

(C) 2019 by the authors. Licensee MDPI, Basel, Switzerland. This article is an open access article distributed under the terms and conditions of the Creative Commons Attribution (CC BY) license (http://creativecommons.org/licenses/by/4.0/). 